\title{
Experimental Study on Reducing the Heat of Curing Reaction of Polyurethane Polymer Grouting Material
}

\author{
Bei Zhang $\mathbb{D}^{1},{ }^{1}$ Baolin Wang $\mathbb{D}^{1}$, Yanhui Zhong $\mathbb{D},{ }^{1}$ Shuangjie Wang $\mathbb{D},^{2}$ Xiaolong Li $^{\mathbb{D}}{ }^{1}$ \\ and Lei Wang ${ }^{3}$ \\ ${ }^{1}$ School of Water Conservancy Engineering, Zhengzhou University, Zhengzhou 450001, China \\ ${ }^{2}$ CCCC First Highway Consultants Co., Ltd., China \\ ${ }^{3}$ Wanhua Energysav Science \& Technology Group Co., Ltd., China
}

Correspondence should be addressed to Baolin Wang; wangbaolin7@126.com, Yanhui Zhong; zhong_yanhui@163.com, Shuangjie Wang; wangshj@ccroad.com.cn, and Xiaolong Li; wennuandeshang@hotmail.com

Received 20 March 2021; Accepted 1 September 2021; Published 4 October 2021

Academic Editor: Nasir M. Ahmad

Copyright ( $) 2021$ Bei Zhang et al. This is an open access article distributed under the Creative Commons Attribution License, which permits unrestricted use, distribution, and reproduction in any medium, provided the original work is properly cited.

Polyurethane polymer grouting material has been effectively applied and promoted in the repair of road damages in nonfrozen areas. However, this material undergoes an exothermic reaction in the curing stage, which can cause a thermal disturbance in the frozen soil subgrade. To minimize the influence of the thermal disturbance of the polyurethane polymer grouting material in the repair of the frozen soil subgrade, an experiment was conducted to reduce the heat of the curing reaction under the influence of different proportions of a foaming agent, high-boiling point solvent, catalyst, and prepolymer. According to these test results, a proportioning scheme for the low exothermic polymer grouting material was formulated. The results indicated that the curing reaction temperature threshold of the polyurethane polymer grouting material was negatively related to the proportion of physical foaming agent (HCFC-141b) and high-boiling point solvent and positively related to the proportion of water weight. In the three stages of rapid temperature rise, slow temperature rise, and constant temperature, the rate of the temperature rise of the low exothermic polymer grouting material was lower than that of the common polymer, and the curing temperature threshold was $30.34 \%$ lower at a value of $101^{\circ} \mathrm{C}$. At a density of $80 \mathrm{~kg} / \mathrm{m}^{3}$, the compressive strength and tensile strength of the low heat release polymer grouting material were lower than those of the common polymer grouting material, thereby ensuring the excellent performance of polyurethane foam and providing a theoretical reference for the rapid repair of frozen soil roadbed diseases.

\section{Introduction}

In the application of highway engineering in an area with frozen subgrade, engineering constructions disturb the geological environment of the frozen soil layer, break the original geological balance state, and make the radiant heat of the road surface transmit downward, causing various adverse geological disasters ([1, 2]; Dong et al., 2020). In recent years, many scholars worldwide have conducted research related to the stability of frozen soil subgrade. For example, Zhang et al. [3] established an empirical model to analyze the distribution law of the temperature field of frozen soil subgrade and describe the entire process of subgrade thawing and frost heave development based on monitoring data of the temperature change of frozen soil subgrade for up to three years. Quan et al. [4] constructed narrow-scale and wide-scale road structures in a frozen soil area and conducted long-term temperature observation and statistical analysis to obtain the temperature change laws of these two types of frozen soil subgrade. Liu et al. [5] summarized the relationship between the peak of roadbed thawing and the depth of seasonal thawing and the vertical settlement deformation characteristics of three different types of roadbeds, based on the annual rate of temperature increase in frozen soil. Varlamov [6] monitored the 


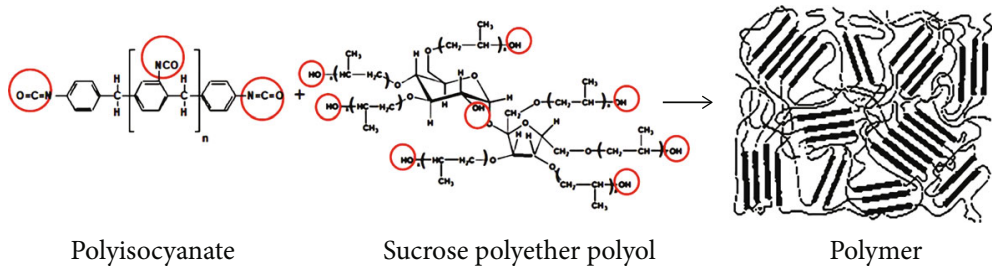

FIGURE 1: Principle of gel reaction.

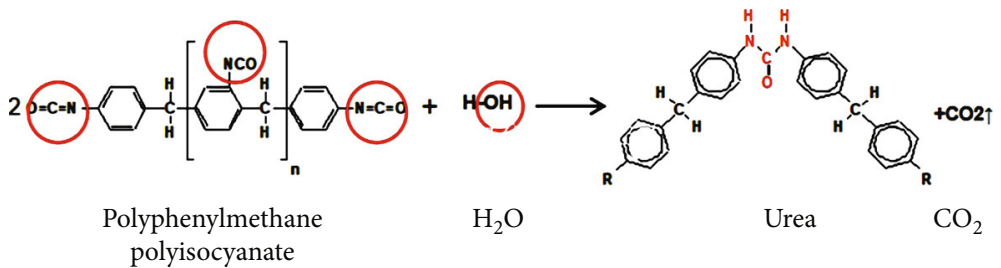

FIGURE 2: Principle of foaming reaction.

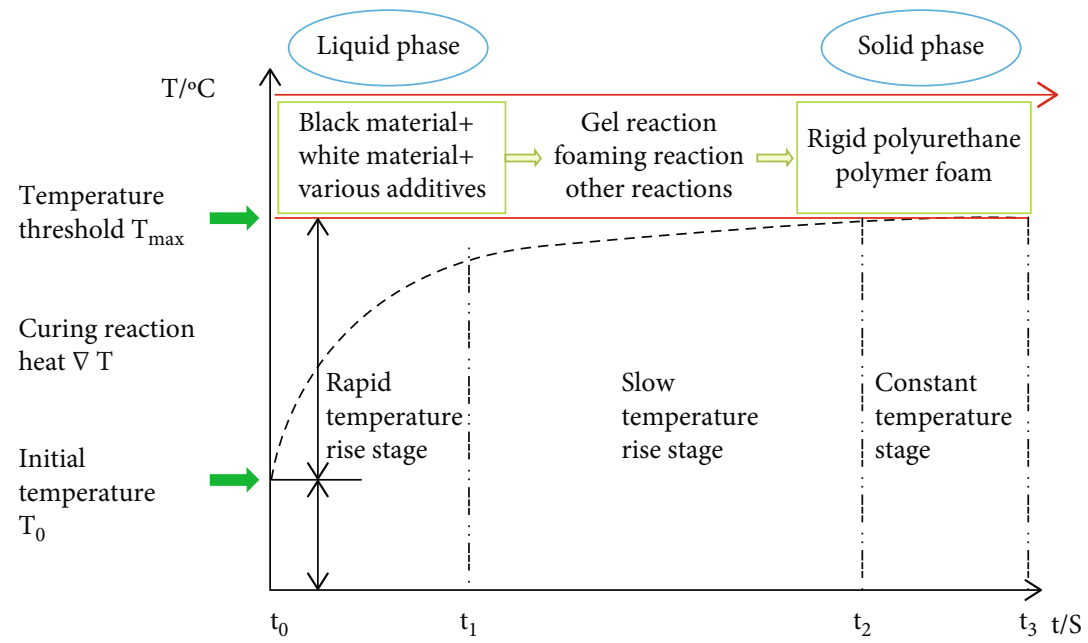

FIGURE 3: Principle of temperature rise in curing stage.

temperature field of frozen soil subgrade in Russia and analyzed the influence of subgrade temperature change on the stability of frozen soil subgrade. Klug et al. [7] demonstrated the inevitable relationship between the surface subsidence and the melting of the frozen layer in the frozen soil area.

The above research results have shown that temperature changes cause uneven settlement and deformation of frozen soil subgrade. However, owing to the seasonal temperature difference and the thermal disturbance of the engineering effect, there is a variation in the heat exchange conditions between the atmosphere and the surface of the frozen soil subgrade, breaking the original thermal equilibrium state of the subgrade and resulting in the redistribution of the temperature field of the frozen soil subgrade. The ice crystals in the frozen soil subgrade absorb the heat transferred from the road surface and melt into liquid water, causing a phase change, which destroys the structure of the frozen soil layer.

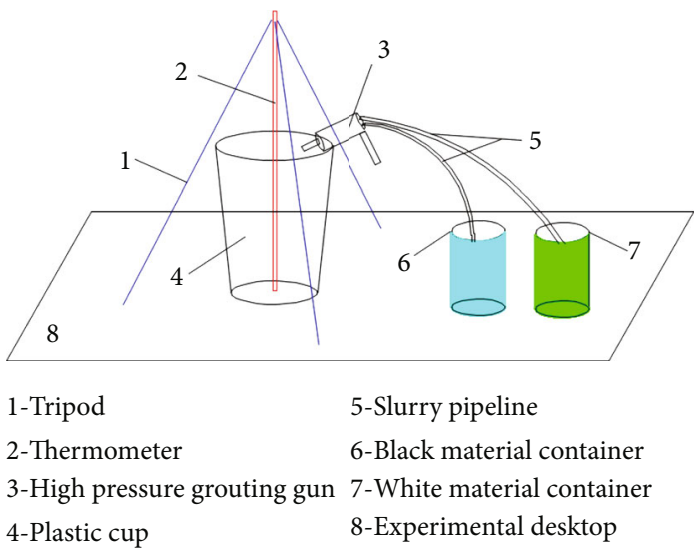

FIgURE 4: The experimental device. 
TABLE 1: Experiment weight proportion scheme of water (\%).

\begin{tabular}{lccccccc}
\hline $\begin{array}{l}\text { Experiment } \\
\text { number }\end{array}$ & $\begin{array}{c}\text { Polyether } \\
1\end{array}$ & $\begin{array}{c}\text { Polyether } \\
2\end{array}$ & $\begin{array}{c}\text { Polyether } \\
3\end{array}$ & $\begin{array}{c}\text { White material } \\
\text { Flame } \\
\text { retardant }\end{array}$ & $\begin{array}{c}\text { Tertiary amine } \\
\text { catalyst }\end{array}$ & $\begin{array}{c}\text { Surface active } \\
\text { agent }\end{array}$ & $\begin{array}{c}\mathrm{H}_{2} \mathrm{O} \text { (weight } \\
\text { proportion) }\end{array}$ \\
\hline 1 & 14.51 & 57.5 & 8.49 & 18 & 0.5 & 1 & 0.01 \\
2 & 14.51 & 57.5 & 8.49 & 18 & 0.5 & 1 & 0.02 \\
3 & 14.51 & 57.5 & 8.49 & 18 & 0.5 & 1 & 0.03 \\
4 & 14.51 & 57.5 & 8.49 & 18 & 0.5 & 1 & 0.04 \\
5 & 14.51 & 57.5 & 8.49 & 18 & 0.5 & 1 & 0.05 \\
\hline
\end{tabular}

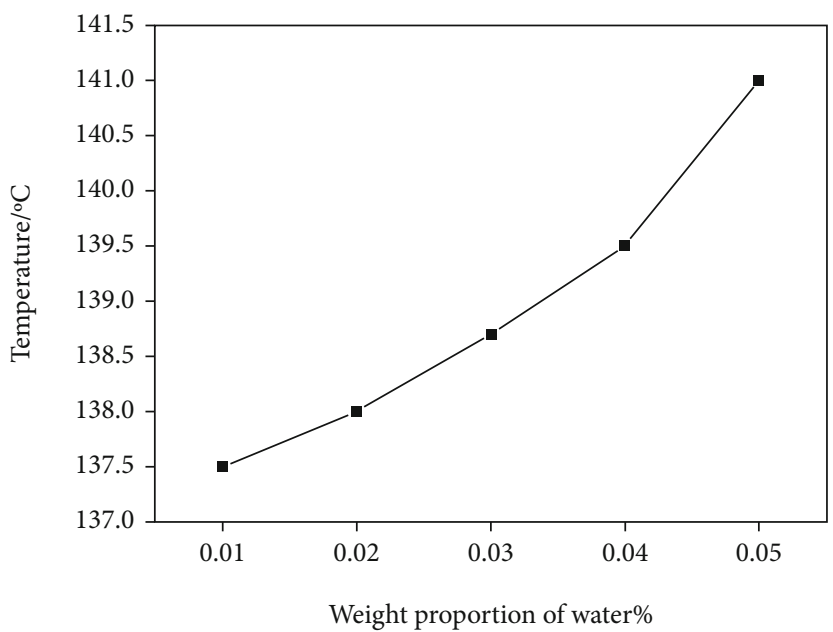

FIGURE 5: Influence of the weight proportion of water on the curing temperature threshold.

Even under a small vehicle cyclic load, the disease of the frozen soil subgrade is inevitable. To deal with the uneven settlement and deformation of the frozen soil subgrade, Ashpiz and Vavrinyuk [8] revealed the deformation mechanism of the subgrade by analyzing its long-term deformation law and proposed a method for strengthening it through the use of spray technology. Lin et al. [9] analyzed the influence of subgrade construction on the stability of frozen soil subgrade and showed that excavation disturbance has the greatest impact on the stability of subgrade. Chai et al. [10] demonstrated that the addition of cement, and additives can change the phase state of water and create a new structural form, thereby improving the compressibility and thawing characteristics of the frozen soil layer of the roadbed. Lvanov and Korotkov [11] used granular foam glassceramic material as the antifreeze layer and analyzed the temperature change law of the frozen soil subgrade. $\mathrm{Wu}$ et al. [12] focused on the analysis of the application of hot rod cooling technology in frozen soil subgrade and revealed the mechanism of the hot rod in the frozen soil subgrade to resist the heat transfer from the road surface. From the above research results, it can be seen that the current treatment methods for uneven settlement and deformation of frozen soil subgrades are mostly focused on the method of excavation and replacement or the use of thermal insulation and heat resistance materials to repave the subgrade. Although this type of treatment method can achieve a satisfactory level of repair, it involves a large amount of engineering, requires a long period of maintenance, and has a significant impact on traffic.

In view of the fact that the roadbed disease repair technology is currently of great concern, the members of this research group have developed a complete set of trenchless polyurethane polymer grouting technologies for the rapid repair of road damages, which has been built upon the current technology [13-16]. However, the currently used common polyurethane polymer grouting material undergoes an exothermic reaction in the curing stage after grouting, and the temperature is as high as approximately $145^{\circ} \mathrm{C}$ [17]. This has a significant influence on the structure of the frozen soil layer of the roadbed and hence cannot be directly applied to repair the frozen ground. Therefore, this study is aimed at developing a low exothermic polymer grouting repair material that can be used in the repair of uneven settlement and deformation of frozen soil subgrade. Firstly, the heat source and phase change process of the polyurethane polymer grouting material were theoretically analyzed, and the principle of temperature rise in the curing stage was revealed. Then, through the design of different proportions of a foaming agent, high-boiling point solvent, catalyst, and 
TABLE 2: Experiment weight proportion scheme of HCFC-141b (\%).

\begin{tabular}{lccccccc}
\hline $\begin{array}{l}\text { Experiment } \\
\text { number }\end{array}$ & $\begin{array}{c}\text { Polyether } \\
1\end{array}$ & $\begin{array}{c}\text { Polyether } \\
2\end{array}$ & $\begin{array}{c}\text { Polyether } \\
3\end{array}$ & $\begin{array}{c}\text { White material } \\
\text { Flame } \\
\text { retardant }\end{array}$ & $\begin{array}{c}\text { Tertiary amine } \\
\text { catalyst }\end{array}$ & $\begin{array}{c}\text { Surface active } \\
\text { agent }\end{array}$ & $\begin{array}{c}\text { HCFC-141b (weight } \\
\text { proportion) }\end{array}$ \\
\hline 1 & 13.16 & 59.5 & 7.84 & 18 & 0.5 & 1 & 1 \\
2 & 13.16 & 59.5 & 7.84 & 18 & 0.5 & 1 & 2 \\
3 & 13.16 & 59.5 & 7.84 & 18 & 0.5 & 1 & 4 \\
4 & 13.16 & 59.5 & 7.84 & 18 & 0.5 & 1 & 6 \\
5 & 13.16 & 59.5 & 7.84 & 18 & 0.5 & 1 & 10 \\
\hline
\end{tabular}

prepolymer, the temperature reduction experiment of polyurethane polymer grouting material was performed. Based on the analysis of the test results, a formula for reducing the heat release of the polyurethane polymer grouting material during the curing stage was formulated. According to the analysis of the test results, the formulation of each component material to reduce the heat released from the polyurethane polymer grouting material during the curing stage was determined. The research results can provide technical support for the rapid repair of highway uniform settlement and deformation in frozen soil areas.

\section{Heating Principle of Polyurethane Polymer Grouting Material in Curing Stage}

2.1. Heat Source. The polyurethane polymer grouting material is produced by the Wanhua Energysav Science and Technology Group Co., Ltd., which is mainly composed of black material (polyphenyl polymethylene isocyanate) and white material (polyether polyol, foaming agent, catalyst, foam stabilizer, and other additives). The chemical reactions between the two materials mainly include gel reaction and foaming reaction. Of these reaction types, the gel reaction refers to the curing reaction of the -NCO groups of the polyisocyanate and the - $\mathrm{OH}$ groups of the polyol, and the resulting urethane groups have an important influence on the strength of the rigid polyurethane foam (the reaction principle is shown in Figure 1). Foaming reaction refers to the reaction of the -NCO groups of polyisocyanate and $\mathrm{H}_{2} \mathrm{O}$ to form $\mathrm{CO}_{2}$ and urea, which has an important influence on the production of foam (the reaction principle is shown in Figure 2) [18].

In addition to the above two main reactions, the curing reaction of polymer grouting material also includes the biuret reaction formed by isocyanate groups and urea groups, the allophanate reaction formed by isocyanate groups and carbamate groups, and the trimerization reaction of isocyanate groups themselves. These chemical reactions are all exothermic reactions.

2.2. Phase Change Process. After a series of chemical reactions, the polymer grouting material changed from a liquid to a foam with a certain strength, resulting in a phase change [19-21].

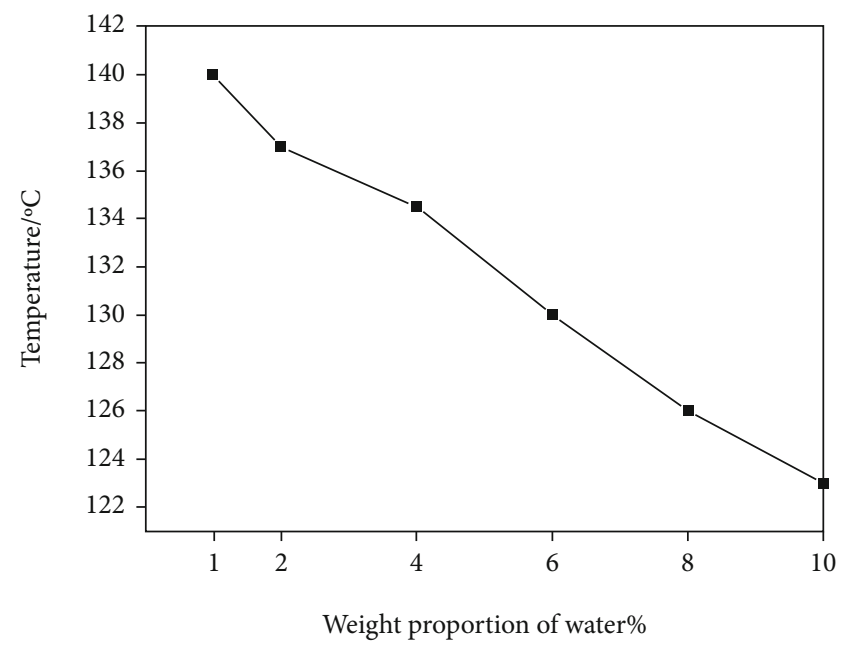

FIGURE 6: Influence of the weight proportion of HCFC-141b on the curing temperature threshold.

When the polymer grouting material is used to repair the uneven settlement and deformation of the frozen soil subgrade, the black and white components of the raw material create a curing reaction under the action of various catalysts and finally form a rigid polyurethane foam with a certain strength [22-24]. Throughout the phase change process, a significant amount of heat is generated owing to the release of chemical bond energy. The principle of temperature rise in the curing stage is depicted in Figure 3.

\section{The Experiment of Reducing the Heat of Curing Reaction}

3.1. Design of Experimental Scheme. In this experiment, a thermometer $(\mathrm{E}+\mathrm{H}$ resistance thermometer, model TMT142R) was used to measure the threshold of the heat of the curing reaction of the polymer grouting material. First, a tripod was used to fix the thermometer in the middle of the bottom of a plastic cup. Then, the experiment proportion schemes of the foaming agent, high-boiling point solvent, catalyst, and prepolymer were made, and the raw black and white components of the polymer grouting material were formed from these 
TABLE 3: Experiment weight proportion scheme of high-boiling point solvent (\%).

\begin{tabular}{lcccccccc}
\hline $\begin{array}{l}\text { Experiment } \\
\text { number }\end{array}$ & $\begin{array}{c}\text { Polyether } \\
1\end{array}$ & $\begin{array}{c}\text { Polyether } \\
2\end{array}$ & $\begin{array}{c}\text { Polyether } \\
3\end{array}$ & $\begin{array}{c}\text { Flame } \\
\text { retardant }\end{array}$ & $\begin{array}{c}\text { Tertiary amine } \\
\text { catalyst }\end{array}$ & $\begin{array}{c}\text { Surface } \\
\text { active agent }\end{array}$ & $\begin{array}{c}\text { HCFC- } \\
141 \mathrm{~b}\end{array}$ & $\begin{array}{c}\text { High-boiling point solvent } \\
\text { (weight proportion) }\end{array}$ \\
\hline 1 & 13.16 & 59.5 & 7.84 & 10 & 0.5 & 1 & 8 & 5 \\
2 & 13.16 & 59.5 & 7.84 & 10 & 0.5 & 1 & 8 & 10 \\
3 & 13.16 & 59.5 & 7.84 & 10 & 0.5 & 1 & 8 & 15 \\
4 & 13.16 & 59.5 & 7.84 & 10 & 0.5 & 1 & 8 & 20 \\
5 & 13.16 & 59.5 & 7.84 & 10 & 0.5 & 1 & 8 & 25 \\
\hline
\end{tabular}

proportions. Finally, the liquid materials (black and white material) of different proportions were injected into the plastic cup at the same time through the high-pressure grouting gun. Then, the whole phase change process of the temperature rise of the polymer grouting material in the curing stage was monitored, and the curing temperature thresholds of different experiment schemes were recorded. The experimental device is shown in Figure 4.

3.2. Effect of the Weight Proportion of Foaming Agent on the Threshold of Curing Temperature. Water is one of the most widely used and cheapest chemical foaming agents in the polyurethane industry, and the proportion of its content directly affects the size and severity of the heat release amount of the polymer foaming reaction [24-26]. In this paper, in order to discuss the influence of the weight proportion of water on the curing temperature threshold of polymer, the experiment weight proportion scheme of water is shown in Table 1, and the experimental results are shown in Figure 5.

It can be seen from Figure 5 that with the decrease in the weight proportion of water, the curing temperature threshold of the polymer decreases gradually, indicating a positive proportional relationship between the two. When the weight proportion of water is $0.05 \%$, the temperature threshold of the polymer during the curing stage is as high as $141^{\circ} \mathrm{C}$. For every $0.01 \%$ decrease in the water weight, the temperature threshold of the polymer curing stage can be reduced by $0.62 \%$. The reason for this phenomenon is that the polyisocyanate in the black material undergoes a foaming reaction when exposed to water, releasing a considerable amount of heat energy, which results in a higher curing temperature when the polymer is formed. When the weight proportion of water is reduced, due to the reduction of the - $\mathrm{OH}$ groups in water, the chemical bond of some of the -NCO groups in the polyisocyanate cannot be completely released. Therefore, the degree of intensity in the foaming reaction is reduced, resulting in a significant decrease in the temperature threshold of the polymer material during the curing stage.

In view of this relationship, in order to reduce the temperature threshold of polyurethane polymer grouting material in the curing stage, it is necessary to reduce the weight proportion of water in the white material. However, as the weight proportion of water decreases, the density and strength of the polymer foam also decrease. Therefore,

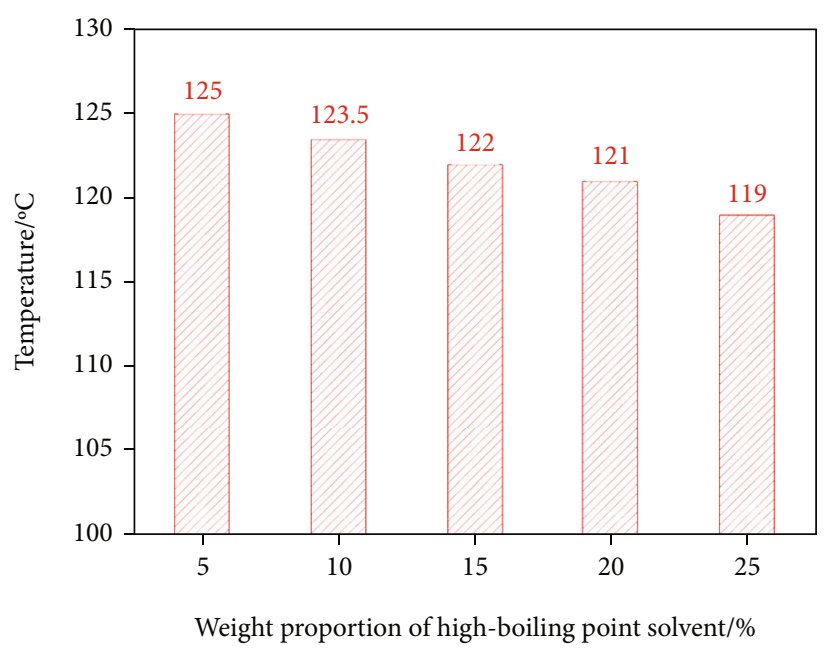

FIGURE 7: Influence of the weight proportion of high-boiling point solvent on the curing temperature threshold.

in order to ensure the high density and strength of the low exothermic polymer grouting material developed in this study, a physical foaming agent, monofluorodichloroethane (HCFC-141b), was added to the white material. HCFC$141 \mathrm{~b}$ is a kind of low-boiling point compound, which can absorb the heat of the curing reaction of the polymer and discharge it by gasification. The experiment weight proportion scheme of HCFC-141b is shown in Table 2, and the experimental results are shown in Figure 6.

It can be seen from Figure 6 that the weight proportion of the physical foaming agent HCFC-141b is inversely related to the threshold of the curing temperature of the polymer. With the increase in the weight proportion of the physical foaming agent HCFC-141b, the curing temperature threshold of the polymer decreases gradually. When the weight proportion of the physical foaming agent HCFC$141 \mathrm{~b}$ is $10 \%$, the temperature threshold of the polymer during the curing stage is reduced to $123^{\circ} \mathrm{C}$. For an average increase of $1 \%$ in the weight proportion of HCFC-141b, the curing temperature threshold is reduced by $1.2 \%$.

3.3. Effect of the Weight Proportion of High-Boiling Point Solvent on the Threshold of Curing Temperature. The specific 
TABLE 4: Experiment scheme of catalyst combination (\%).

\begin{tabular}{|c|c|c|c|c|c|c|c|c|}
\hline $\begin{array}{l}\text { Combination } \\
\text { scheme }\end{array}$ & $\begin{array}{l}\text { Combined } \\
\text { polyether }\end{array}$ & $\begin{array}{l}\text { Flame } \\
\text { retardant }\end{array}$ & $\begin{array}{c}\text { White material } \\
\text { High-boiling point } \\
\text { solvent }\end{array}$ & $\begin{array}{c}\text { Surface active } \\
\text { agent }\end{array}$ & $\begin{array}{c}\text { HCFC- } \\
141 b\end{array}$ & $\begin{array}{l}\text { Tertiary amine } \\
\text { catalyst }\end{array}$ & $\begin{array}{l}\text { Potassium } \\
\text { acetate }\end{array}$ & $\begin{array}{c}\text { Organotin } \\
\text { catalysts }\end{array}$ \\
\hline 1 & 67.0 & 10 & 15 & 1 & 8 & 0.5 & 0 & 0 \\
\hline 2 & 67.0 & 10 & 15 & 1 & 8 & 0.2 & 0.3 & 0 \\
\hline 3 & 67.0 & 10 & 15 & 1 & 8 & 0.2 & 0 & 0.3 \\
\hline 4 & 67.0 & 10 & 15 & 1 & 8 & 0.2 & 0.1 & 0.2 \\
\hline
\end{tabular}

heat capacity of the high-boiling point solvent is larger, and the endothermic capacity is stronger. Adding an appropriate amount of high-boiling point solvent to the white material can absorb part of the heat of the reaction, thereby lowering the curing temperature threshold of the polymer. The experiment weight proportion scheme of the high-boiling point solvent is shown in Table 3 , and the experimental results are shown in Figure 7.

It can be seen from Figure 7 that as the weight proportion of the high-boiling solvent is increased, the temperature threshold of the polymer during the curing stage gradually decreases. When the weight proportion of the high-boiling point solvent is $5 \%$, the curing temperature threshold of the polymer grouting material is $125^{\circ} \mathrm{C}$. When the weight proportion of the high-boiling point solvent increased to $25 \%$, the threshold of the curing temperature is only $119^{\circ} \mathrm{C}$, a decrease of $6^{\circ} \mathrm{C}$. According to the experimental results, it can be concluded that an appropriate increase of the high-boiling point solvent in the polymer grouting material can absorb part of the heat of the curing reaction and effectively reduce the curing temperature threshold of the polymer grouting material. However, considering the strength requirements of polymer foam, the weight proportion of the high-boiling point solvent in the white material should not exceed $25 \%$.

3.4. Effect of the Weight Proportion of Catalyst on the Threshold of Curing Temperature. During the curing reaction of the polymer, the use of different types of catalysts can effectively reduce the activation energy, adjust the reaction time between many competing reactions, and achieve an equilibrium state. For example, the tertiary amine catalysts have a strong catalytic effect on the reaction of - NCO groups and $\mathrm{H}_{2} \mathrm{O}$ and - $\mathrm{NCO}$ and hydroxyl groups, in the curing process of polyurethane foam, especially for -NCO groups and $\mathrm{H}_{2} \mathrm{O}$. The catalytic effect of organometallic catalysts on the reaction of -NCO groups and hydroxyl groups is more obvious. In order to study the effect of different catalyst combinations on the curing temperature threshold of polymers, the experiment scheme of catalyst combinations is shown in Table 4, and the experimental results are shown in Figure 8.

It can be seen from Figure 8 that when using Combination Scheme 2, the curing temperature threshold of the polymer is $127^{\circ} \mathrm{C}$, and the temperature reduction effect is not obvious. When Combination Scheme 3 is used, the threshold of the curing temperature of the polymer is reduced to $108^{\circ} \mathrm{C}$, and the temperature reduction effect is obvious. The

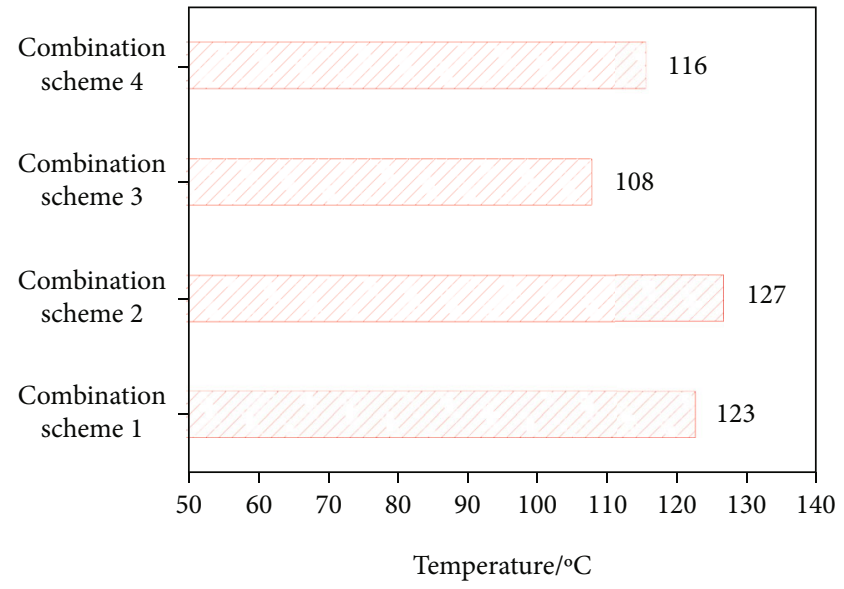

FIgURE 8: Influence of different catalyst combination schemes on the curing temperature threshold.

sensitivity of the four different catalyst combinations on the temperature threshold of the polymer grouting material in the curing stage can be arranged from highest to lowest as Combination Scheme $3>$ Combination Scheme $4>$ Combination Scheme $1>$ Combination Scheme 2. Therefore, in the development of the low exothermic polymer grouting material, Combination Scheme 3 was selected to achieve the purpose of reducing the temperature threshold of the polymer during the curing stage.

\subsection{Effect of Prepolymerization Modification Reaction on the} Threshold of Curing Temperature. Adding an appropriate amount of physical foaming agent and high-boiling point solvent to the white material can reduce the threshold of the curing temperature to a certain extent, but it has an adverse effect on the strength of the polyurethane polymer foam. To reduce the temperature threshold of the curing stage while ensuring the strength of the polyurethane polymer foam, the polyol and isocyanate were reacted in the reactor to form prepolymers with different NCO contents. The prepolymers were obtained by reacting polyphenyl polymethylene isocyanate and polyethylene glycol as the main raw materials. For Prepolymer 1 to Prepolymer 4, the NCO content was $18.5 \%, 21.4 \%, 16.6 \%$, and $23.5 \%$, respectively. The experiment scheme with different prepolymer contents is presented in Table 5, and the experimental results are depicted in Figure 9. 
TABLE 5: Experiment scheme with different prepolymer contents (\%).

\begin{tabular}{lccccccc}
\hline $\begin{array}{l}\text { Experiment } \\
\text { number }\end{array}$ & $\begin{array}{c}\text { White } \\
\text { material }\end{array}$ & $\begin{array}{c}\text { Prepolymer 1 } \\
\text { (NOC of 18.5\%) }\end{array}$ & $\begin{array}{c}\text { Prepolymer 2 } \\
\text { (NOC of 21.4\%) }\end{array}$ & $\begin{array}{c}\text { Prepolymer 3 } \\
\text { (NOC of 16.6\%) }\end{array}$ & $\begin{array}{c}\text { Prepolymer 4 } \\
\text { (NOC of 23.5\%) }\end{array}$ & $\begin{array}{c}\text { Polyphenyl } \\
\text { polymethylene } \\
\text { isocyanate }\end{array}$ & $\begin{array}{c}\text { High-boiling } \\
\text { point solvent }\end{array}$ \\
\hline 1 & 100 & 45 & 0 & 0 & 0 & 50 & 5 \\
2 & 100 & 0 & 45 & 0 & 0 & 50 & 5 \\
3 & 100 & 0 & 0 & 45 & 0 & 50 & 5 \\
4 & 100 & 0 & 0 & 0 & 45 & 50 & 5 \\
\hline
\end{tabular}

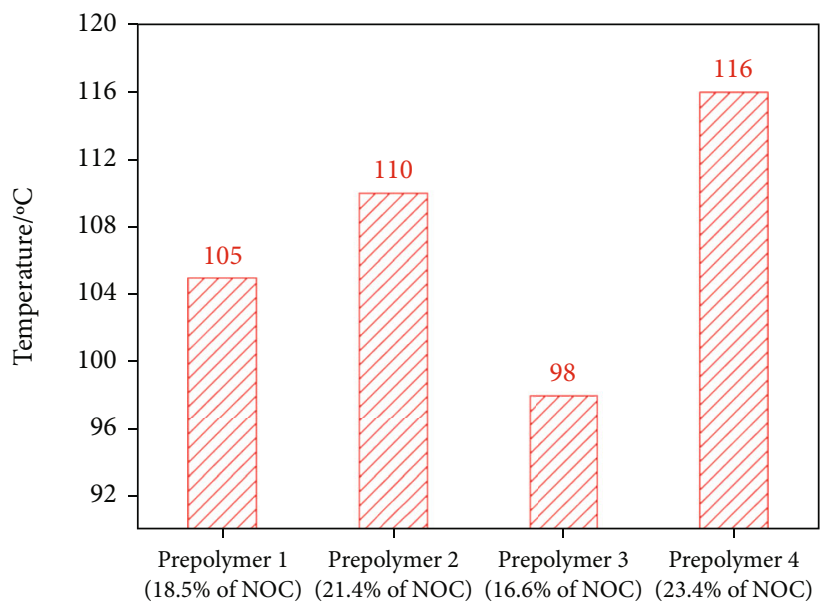

Figure 9: Influence of the prepolymers with different NOC content on the curing temperature threshold.

It can be seen from Figure 9 that the order of the influence of the prepolymers with different NOC contents on the temperature threshold of the polymer curing stage can be presented from greatest to least as Prepolymer 3 (NOC content $16.6 \%)>$ Prepolymer 1 (NOC content $18.5 \%)>$ Prepolymer 2 (NOC content 21.4\%) > Prepolymer 4 (NOC content 23.5\%). When Prepolymer 3 is used to replace part of the polyisocyanate in the black material, the temperature threshold of the curing stage of the polymer is only $98^{\circ} \mathrm{C}$, which is $15.5 \%$ lower than the curing temperature threshold of $116^{\circ} \mathrm{C}$, which corresponds to Prepolymer 4. The experimental results reveal that during the formation of the prepolymer, the polymer releases part of the heat of the chemical reaction in advance. Therefore, the use of Prepolymer 3 to replace part of the polyisocyanate in the black material can effectively reduce the temperature threshold of the polymer during the curing stage.

\section{Road Performance of Low Exothermic Polymer Grouting Material}

4.1. Proportioning Scheme of Low Exothermic Polymer Grouting Material. In this study, in order to reduce the temperature threshold of the polymer grouting material in the curing stage and at the same time to ensure its strength requirements, the proportion of different blowing agents, high-boiling point solvents, catalysts, and prepolymers in the polymer raw material was formulated. The best proportion scheme of the low exothermic polymer grouting material is shown in Table 6 .

4.2. Law of Temperature Change of Low Exothermic Polymer Grouting Material in the Curing Stage. Using the proportion scheme shown in Table 6, the temperature threshold of the low exothermic polymer grouting material during the curing stage was measured (as shown in Figure 10). Figure 11 shows the temperature curves of the common polymer and low exothermic polymer grouting material in the curing stage. It can be seen from Figure 11 that during the rapid temperature rise stage, the average temperature of the common polymer grouting material rises by $0.91^{\circ} \mathrm{C}$ per second, and the average temperature of the low exothermic polymer grouting material rises by $0.64^{\circ} \mathrm{C}$ per second, for a heating rate reduction of $29.67 \%$. In the stage of slow temperature rise, the average temperature of the common polymer grouting material rises by $0.14^{\circ} \mathrm{C}$ per second, and the average temperature of the low exothermic polymer grouting material rises by $0.08^{\circ} \mathrm{C}$ per second, for a heating rate reduction of $42.86 \%$. In the constant temperature stage, the temperature threshold of the common polymer grouting material is $145^{\circ} \mathrm{C}$, but the temperature threshold of the low exothermic 
TABLE 6: Proportions of low exothermic polymer grouting material (\%).

\begin{tabular}{|c|c|c|c|c|c|c|c|c|c|c|c|}
\hline \multirow{2}{*}{ White material } & Component & Pre 1 & Pre 2 & Pre 3 & $\begin{array}{l}\text { Flame } \\
\text { retardant }\end{array}$ & $\begin{array}{l}\text { High-boiling } \\
\text { point solvent }\end{array}$ & $\begin{array}{c}\text { Surface } \\
\text { active agent }\end{array}$ & $\begin{array}{c}\text { Tertiary } \\
\text { amine catalyst }\end{array}$ & $\begin{array}{l}\text { Organotin } \\
\text { catalysts }\end{array}$ & $\mathrm{H}_{2} \mathrm{O}$ & $\begin{array}{l}\text { HCFC- } \\
141 b\end{array}$ \\
\hline & $\begin{array}{c}\text { Weight } \\
\text { proportion (\%) }\end{array}$ & 10.16 & 43.96 & 5.28 & 18 & 15 & 1 & 0.2 & 0.3 & 0.1 & 6 \\
\hline \multirow[t]{2}{*}{ Black material } & Component & $\begin{array}{r}\text { Prepo } \\
3 \text { (NC } \\
16.6\end{array}$ & $\begin{array}{l}\text { lymer } \\
\mathrm{DC} \text { of } \\
6 \%)\end{array}$ & \multicolumn{5}{|c|}{ Polyphenyl polymethylene isocyanate } & \multicolumn{3}{|c|}{ High-boiling point solvent } \\
\hline & $\begin{array}{c}\text { Weight } \\
\text { proportion (\%) }\end{array}$ & \multicolumn{2}{|c|}{45} & \multicolumn{5}{|c|}{50} & \multicolumn{3}{|c|}{5} \\
\hline
\end{tabular}

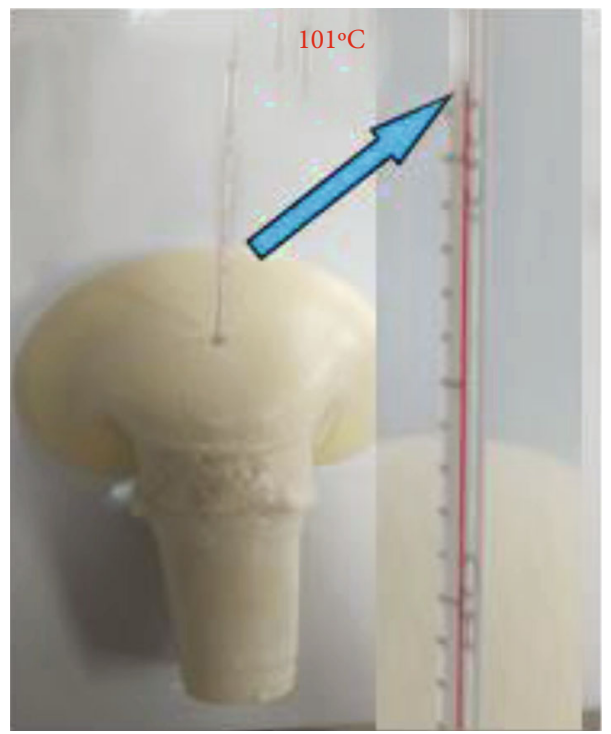

Figure 10: Temperature threshold of low exothermic polymer grouting material.

polymer grouting material is only $101^{\circ} \mathrm{C}, 30.34 \%$ lower than that of the common polymer.

4.3. Physical and Mechanical Properties of Low Exothermic Polymer Grouting Material. The grouting material of the common polymer and low exothermic polymer was tested in the laboratory, and the physical and mechanical indexes of the two materials were obtained, as shown in Figure 12. It can be seen from Figure 12 that at a density of $80 \mathrm{~kg} / \mathrm{m}^{3}$, the compressive strength of the low exothermic polymer grouting material is $0.7 \mathrm{MPa}$, and the tensile strength is $0.45 \mathrm{MPa}$. Compared with the common polymer grouting material, the compressive strength of the low exothermic polymer grouting material is reduced by $6.67 \%$, and the tensile strength is reduced by $6.25 \%$. In addition, due to the presence of the physical foaming agent (HCFC-141b) and catalyst in the low exothermic polymer grouting material, the reaction time of the foaming reaction was adjusted. As a result, the foam shrinkage of polyurethane foam in water is less than $3 \%$, and the foaming time is only 13 s. Compared with common polymer grouting material, the foaming time is increased by $23 \%$.

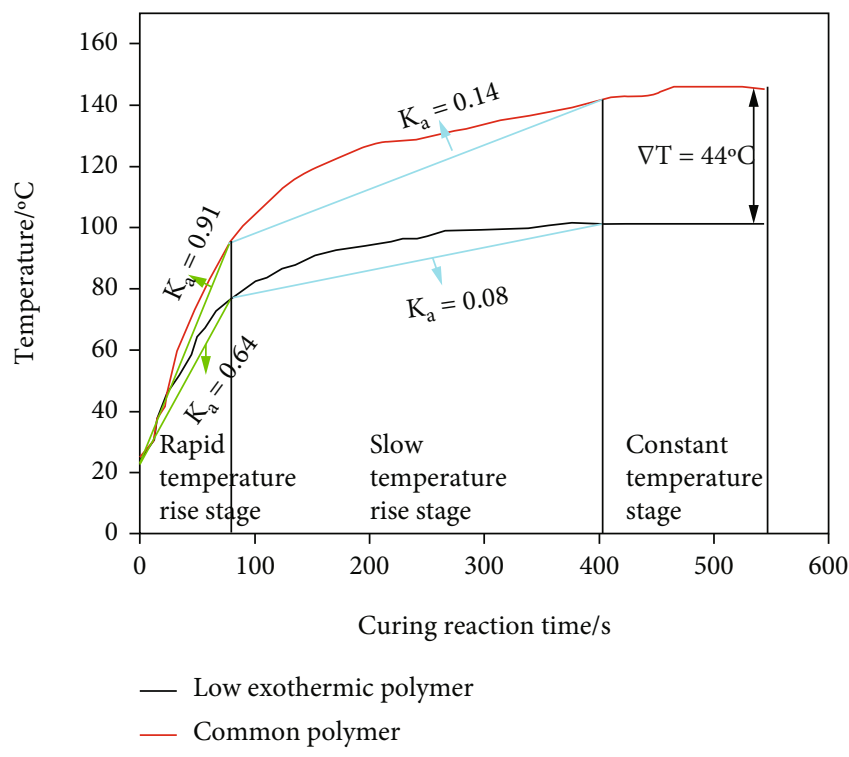

FIGURE 11: Temperature curve during curing stage. 


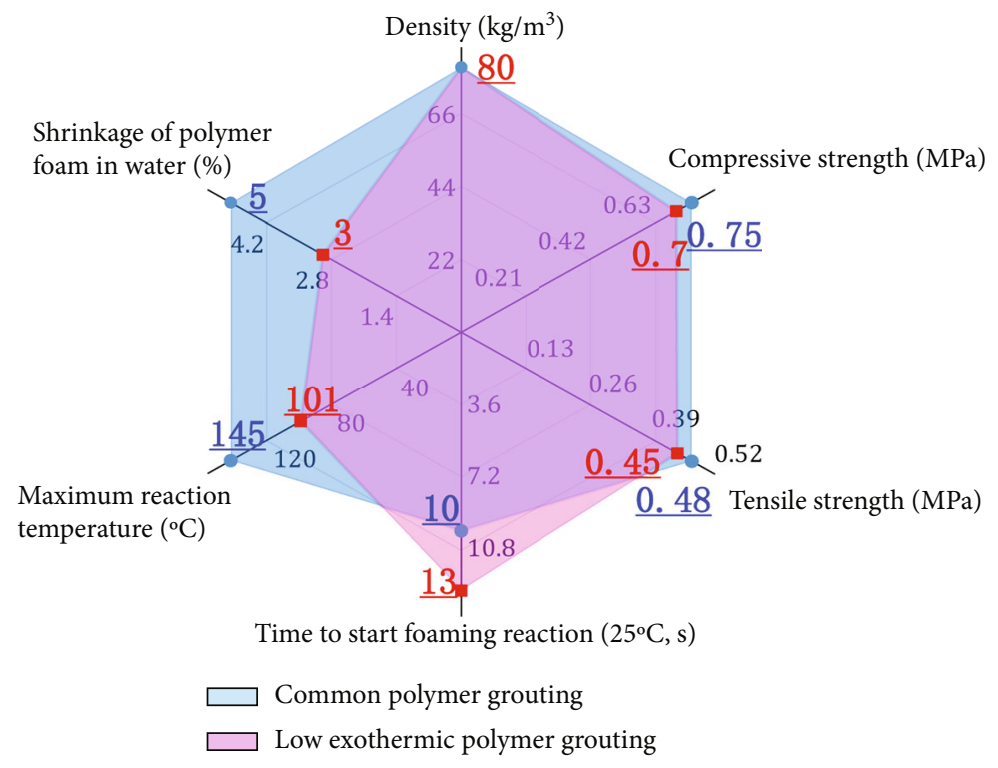

FIgURE 12: Comparison of physical and mechanical indicators.

\section{Conclusion}

In this study, for the purpose of researching and developing a polymer grouting material that can quickly repair the uneven settlement and deformation of frozen soil roadbeds, an experiment was carried out around the key engineering problem of reducing the heat of the curing reaction of polyurethane polymer grouting material. The research conclusions are as follows:

(1) The temperature threshold of the polyurethane polymer grouting material during the curing stage gradually decreased with the increase of the weight proportion of the physical foaming agent (HCFC$141 \mathrm{~b}$ ) and the high-boiling point solvent and gradually increased with the increase of the weight proportion of the water. Combination Scheme $3(0.2 \%$ of tertiary amine catalyst and 0.3 of organotin catalysts) and Prepolymer 3 (NOC of 16.6\%) had the best effect on reducing the temperature threshold

(2) In the three stages of rapid temperature rise, slow temperature rise, and constant temperature in the curing reaction of the polymer grouting material, the rate of temperature rise in the low exothermic polymer grouting material was lower than that of the common polymer grouting material, and the temperature threshold, $101^{\circ} \mathrm{C}$, represented a reduction of $30.34 \%$

(3) Compared with the common polymer grouting material, at a density of $80 \mathrm{~kg} / \mathrm{m}^{3}$, the compressive strength of the low exothermic polymer grouting material was only reduced by $6.67 \%$, and the tensile strength was only reduced by $6.25 \%$. This shows that the low exothermic polymer grouting material still had excellent strength

\section{Data Availability}

The data used to support the findings of this study are available from the corresponding author upon request.

\section{Conflicts of Interest}

The authors declared that they have no conflicts of interest in this work.

\section{Acknowledgments}

We acknowledge the support received from the National Key Research and Development Plan (Grant No. 2018YFB1600200), the National Natural Science Foundation of China (Grant Nos. 51878622 and 51878624), the Major Scientific and Technological Special Project in Henan (Grant No. 181100310400), the Henan Science Fund for Distinguished Young Scholars (Grant No. 202300410354), the Program for Science and Technology Innovation Talents in Universities of Henan Province (Grant No. 19HASTIT041), the Key Research Projects of Higher Education in Henan Province (Grant No. 18A580001), and the Science and technology R \& D project (Grant No. 2017-ZJKJ-PTJS03).

\section{References}

[1] P. Wang, E. L. Liu, D. Zhang, X. Liu, G. Zhang, and B. Song, "An elastoplastic binary medium constitutive model for saturated frozen soils," Cold Regions Science and Technology, vol. 174, pp. 103055-103112, 2020.

[2] Z. Y. Liu, F. Q. Cui, J. B. Chen, L. Jin, W. Wang, and W. Zhang, "Study on the permafrost heat transfer mechanism and reasonable interval of separate embankment for the QinghaiTibet expressway," Cold Regions Science and Technology, vol. 170, pp. 102952-102959, 2020. 
[3] Y. Z. Zhang, Y. L. Du, and B. C. Sun, "Temperature distribution analysis of high-speed railway roadbed in seasonally frozen regions based on empirical model," Cold Regions Science and Technology, vol. 114, pp. 61-72, 2015.

[4] L. Quan, B. Tian, K. M. Niu, and S. Li, "Field observation and analysis on thermal effects of wide asphalt pavementembankment structure in high-altitude permafrost region," China Civil Engineering Journal, vol. 52, no. 3, pp. 111-119, 2019.

[5] J. K. Liu, B. W. Tai, and J. H. Fang, "Ground temperature and deformation analysis for an expressway embankment in warm permafrost regions of the Tibet plateau," Permafrost and Periglacial Processes, vol. 30, no. 3, pp. 208-221, 2019.

[6] S. P. Varlamov, "Thermal monitoring of railway subgrade in a region of ice-rich permafrost, Yakutia, Russia," Cold Regions Science and Technology, vol. 155, pp. 184-192, 2018.

[7] C. Klug, L. Rieg, P. Ott, M. Mössinger, R. Sailer, and J. Stötter, "A multi-methodological approach to determine permafrost occurrence and ground surface subsidence in mountain terrain, Tyrol, Austria," Permafrost and Periglacial Processes, vol. 28, no. 1, pp. 249-265, 2017.

[8] E. S. Ashpiz and T. S. Vavrinyuk, "Strengthening long-term embankments maintained on permafrost soils," Sciences in Cold and Arid Regions, vol. 9, pp. 317-320, 2017.

[9] Z. J. Lin, F. J. Niu, J. Xu, Z. Y. Xu, and P. Wang, "The effect of embankment construction on permafrost in the Tibetan Plateau," Journal of Glaciology and Geocryology, vol. 31, pp. 1127-1136, 2009.

[10] M. T. Chai, J. M. Zhang, W. Ma, Z. Yin, Y. Mu, and H. Zhang, "Thermal influences of stabilization on warm and ice-rich permafrost with cement: Field observation and numerical simulation," Applied Thermal Engineering, vol. 148, pp. 536-543, 2019.

[11] K. S. Ivanov and E. A. Korotkov, "Investigation of the effect of a layer of granulated foam-glass ceramic on the temperature conditions of frozen soil," Soil Mechanics and Foundation Engineering, vol. 54, no. 5, pp. 349-355, 2017.

[12] J. Q. Wu, Y. Y. Xin, W. X. Xu, and T. Sun, "Research on application of hot rod in island-shaped permafrost subgrade engineering of Genla highway," Journal of Glaciology and Geocryology, vol. 40, no. 5, pp. 943-950, 2018.

[13] F. M. Wang, Y. F. Fan, and C. C. Guo, "Practice of non-waterreacting polymer grouting treatment to seepage," Journal of Hydroelectric Engineering, vol. 37, no. 10, pp. 1-11, 2018.

[14] Y. Wei, F. M. Wang, X. Gao, and Y. Zhong, "Microstructure and fatigue performance of polyurethane grout materials under compression," Journal of Materials in Civil Engineering, vol. 29, no. 9, article 04017101, 2017.

[15] R. Wang, F. M. Wang, J. G. Xu, Y. Zhong, and S. Li, "Full-scale experimental study of the dynamic performance of buried drainage pipes under polymer grouting trenchless rehabilitation," Ocean Engineering, vol. 181, pp. 121-133, 2019.

[16] X. L. Li, F. M. Wang, and Y. H. Zhong, "Simulation on flowing and diffusing of expansible grouting material of polymer in two-dimensional fractures," Chinese Journal of Rock Mechanics and Engineering, vol. 34, no. 6, pp. 1188-1197, 2015.

[17] M. S. Shi and W. Y. Xia, "Experimental research on curing temperature of polyurethane polymer," New Chemical Materials, vol. 42, no. 7, pp. 133-135, 2014.
[18] B. Zhang, B. Wang, Y. Zhong, S. Wang, X. Li, and S. Wang, "Temperature Field Variation Law of Low Exothermic Polymer Grouting Material in Repairing Void Damage of Frozen Soil Subgrade," Advances in Materials Science and Engineering, vol. 2021, 11 pages, 2021.

[19] U. Berardi and J. Madzarevic, "Microstructural analysis and blowing agent concentration in aged polyurethane and polyisocyanurate foams," Applied Thermal Engineering, vol. 164, article 114440, 2020.

[20] H. Y. Fang, Y. J. Su, X. du, F. Wang, and B. Li, "Experimental and numerical investigation on repairing effect of polymer grouting for settlement of high-speed railway unballasted track," Applied Sciences-Basel, vol. 9, no. 21, p. 4496, 2019.

[21] C. C. Guo, B. Sun, D. P. Hu, F. Wang, M. Shi, and X. Li, “A field experimental study on the diffusion behavior of expanding polymer grouting material in soil," Soil Mechanics and Foundation Engineering, vol. 56, no. 3, pp. 171-177, 2019.

[22] Z. Sun, J. Zhang, and Y. Sun, "Feasibility of a polymer foaming agent as a grouting material for broken coal masses," Advances in Civil Engineering, vol. 2019, Article ID 9084861, 9 pages, 2019.

[23] M. M. Hao, X. L. Li, Y. H. Zhong, B. Zhang, D. Jin, and G. Chen, "Numerical simulation of polymer grout diffusion in a single fracture," AIP Advances, vol. 8, no. 10, article 105329, 2018.

[24] T. Zhang, C. F. Xiao, J. Zhao, X. Liu, Y. Huang, and D. Ji, "Graphite powder coated polyurethane sponge hollow tube as a high-efficiency and cost-effective oil-removal materials for continuous oil collection from water surface," Journal of Applied Polymer Science, vol. 137, no. 31, pp. 48921-49110, 2019.

[25] Y. C. Chen, H. Zhang, Z. D. Zhu, and S. Fu, "High-value utilization of hydroxymethylated lignin in polyurethane adhesives," International Journal of Biological Macromolecules, vol. 152, pp. 775-785, 2020.

[26] C. Caglayan, I. Osken, A. Ataalp, H. S. Turkmen, and H. Cebeci, "Impact response of shear thickening fluid filled polyurethane foam core sandwich composites," Composite Structures, vol. 243, article 112171, 2020. 